\title{
The Application of Information Technologies for the Development of the Arab Bridge Maritime Company Maritime Transport Operations
}

\author{
Faisal S. Assaf \\ MBA Student, Jordan University \\ Aqaba, The Hashemite Kingdome of Jordan \\ E-mail: fassaf@abmaritime.com.jo
}

Received: May 29, 2014 Accepted: June 11, 2014 Published: June 24, 2014

doi:10.5296/csbm.v1i1.5703ＵRL: http://dx.doi.org/10.5296/csbm.v1i1.5703

\begin{abstract}
The Arab Bridge Maritime Company suffers seasonal trailers congestions on its liner service across the Gulf of Aqaba due to several problems, this research focuses on identifying the trailers congestions problems, constraints, and business challenges affecting the efficiency of the maritime and land transport operation on the overall transportation chain of supply for the company and carry out the necessary reengineering process on the day to day operations processes for a better ships efficient operation, smooth flow of trailers, and better customer satisfaction by utilizing three information technologies, the LRIT, RFID and SMS, taking into consideration the business environment, i.e. limited city and port infrastructure, seasonal increase in trailers movement, available technologies in the market and ABM ships capacity.
\end{abstract}

Keywords: Supply chain management, Theory of constraints, RORO passengers ships 


\section{Ill Macrothink \\ Case Studies in Business and Management \\ ISSN 2333-3324 \\ 2014, Vol. 1, No. 1}

\section{Introduction}

Thousands of businesses have reengineered work in order to focus employees on processes that clearly provide value to customers, and Managers who aren't ready to promote a collaborative culture may be better off leaving their functional departments intact (Majchrzak \& Wang, 1996). As people and companies rely on basic infrastructures to function, businesses also rely on an information systems infrastructure (consisting of hardware, software, networks, data, facilities, human resources, and services) to support their decision making, business processes and competitive strategy (Valacich \& Schneider, 2013).

Therefore, this research provided an overview for a proposed solution for improving the maritime and land transportation systems across Aqaba Port in Jordan by identifying the operations constraints and utilizing and merging the available Information technologies and applications to develop and design a framework and communication platform systems such as the RFID, SMS and LRIT, to monitor and control the maritime transportation facilities (Ports and Ships) along with the land transportation facilities (Trailers and Waiting areas) to mainly avoid congestions, increase ship's loading efficiency, reduce cost, add competitive values and profitability to the ships and trailers transport operators and owners.

\section{General Overview}

The Arab Bridge Maritime company is a Joint venture ship owner and operator company established in 1987, exclusively running four RoRo passengers ships, and three High Speed Crafts on Full Liner Service terms between Aqaba port in Jordan and Nowaibeh port in Egypt on a 37 sailing miles across the Gulf of Aqaba.

The company exclusively uses a two berths terminal (Yarmouk port) in Aqaba and 4 berths terminals port in Noweiba working in passengers, trailers and cars transportation. It transfers about 55,000 trailers every year (ABM statistics, 2014). This massive amount of trailers move on different average numbers around the year and turn to increase dramatically during Winter and Spring seasons with about 70\% increase in its numbers (i.e., from 11800 to 18500 per season in 2013, see figure 1, ABM Trailers Seasonal Transportation statistics) where thousands of trailers rush between Asia and Africa on board ABM ships (ABM statistics, 2014) within these two seasons. 


\section{Macrothink}

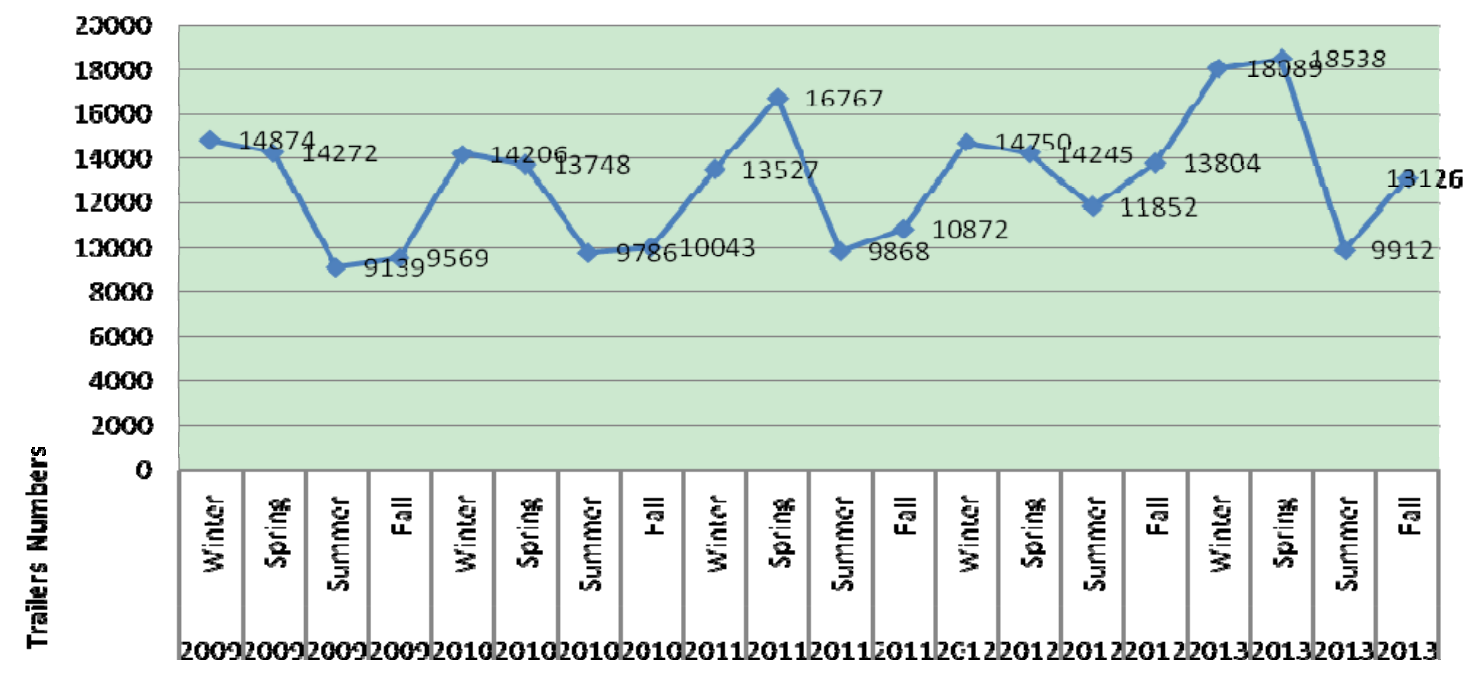

Figure 1. The Arab Bridge Maritime Co. trailers seasonal transportation (2009 to 2013)

The total ABM ship's capacity is about 140 trailers, 30 busses, 650 cars and 3300 passenger seats (http://abmaritime.com.jo). However, ships loading capacity varies with different scenarios of loading (for example, FB Sinaa can either take 65 busses, or 45 trailers or 250 cars apart from its 350 pax capacity). This research focused on the trailers land movement and flow constraints within their SCM to identify the seasonal congestions, where the seasonal variation in trailers numbers arriving at both ends affects the efficiency of the whole chain of transport leading to delays in the trailers backhauls during the peak seasons to the extent that it creates heavy congestions of trailers (i.e., up to 700 trailers each end) with heavy commercial losses, because the trailer's round trip on roads (Amman, Cairo, Amman) is about 24 hours (about $2000 \mathrm{Km}$ ) while most of the trailer traveling time is lost, waiting at ports, customs and other loading/discharging cargo times, the new element of delay is the maritime transport delay where more than 10 to 12 days are lost on their journey, costing up to 20 days for one single round trip, because of the bottleneck created at Aqaba sea and dry ports.

\section{The Problem Solving Approach}

Despite of the core competitive strength in the ABM business such as the exclusivity of the route, where no other operator is permitted to run in the same route, its commitment to the market and responsibility extends to provide the route with the necessary and suitable means of marine transportation (i.e., ships with sufficient capacity) to provide an efficient and smooth flow and movement of passengers, trailers, cars and cargo, therefore the ABM fleet expansion strategy was very well customer oriented, where ships were carefully purchased for its precise specification and upgraded to serve this specific market. Yet during low seasons, the ABM commitment forces it to move ships with great losses, while during peak seasons such as Omra and pilgrim seasons to Mecca, summer vacation with family cars movement from the Arabian Gulf to Egypt, cargo and high citrus products flow, the company's ship's capacities were never compatible with the market requirement/demand or 
able to secure the smooth flow of traffic in time, resulting in heavy congestions on both ends.

As a ship owner and operator company, the ABM needs to keep its relationship with its customers (i.e., passengers, cars, trailers drivers and cargo shippers and consignees) at the best level of understanding and satisfaction, by keeping the trailers liner service under control and diverting its resources to keep up with its operation as safe, fast and cheap as possible during all times and avoid congestions.

To design the necessary Information system framework with the required and applicable system model for (ABM), considering that on redesigning processes, managers should consider the constraints and possibilities provided by technology, the work process, the existing organizational structure and the organization's strategic mission (Majchrzak \& Wang 1996), the research used two practices to identify, the operation constraints and the relevant IT system applicable for the ABM operation, therefore concentrated on developing and utilizing three main Information Technologies (i.e., hardware, software, networks, data, facilities, and services) the LRIT for ship tracking, the SMS for communication and RFID technology for trailers flow, tracking, control and follow up.

The first practice adapted was the model illustrated in the Management Information System book (Laudon \& laudon, 2014) for identifying the business challenges, business solutions and the relevant actions taken on the Management, Organization and Technology perspectives to develop, implement and design a Management Information system within the intermodal transport chain of supply at ABM to overcome these difficulties and constrains (see figure 2, The project main plan of action).

The second practice is the Theory of Constraints (TOC) as a systematic management approach, developed by Eli Goldratt, that focuses on actively managing those constraints that impedes a firm's progress toward its goal of maximizing profits and effectively using its resources, it outlines a deliberate process for identifying and overcoming constraints. The process focuses not just on the efficiency of individual processes but also on the bottlenecks that constrain the system as a whole (Krajewaski et al., 2013). 


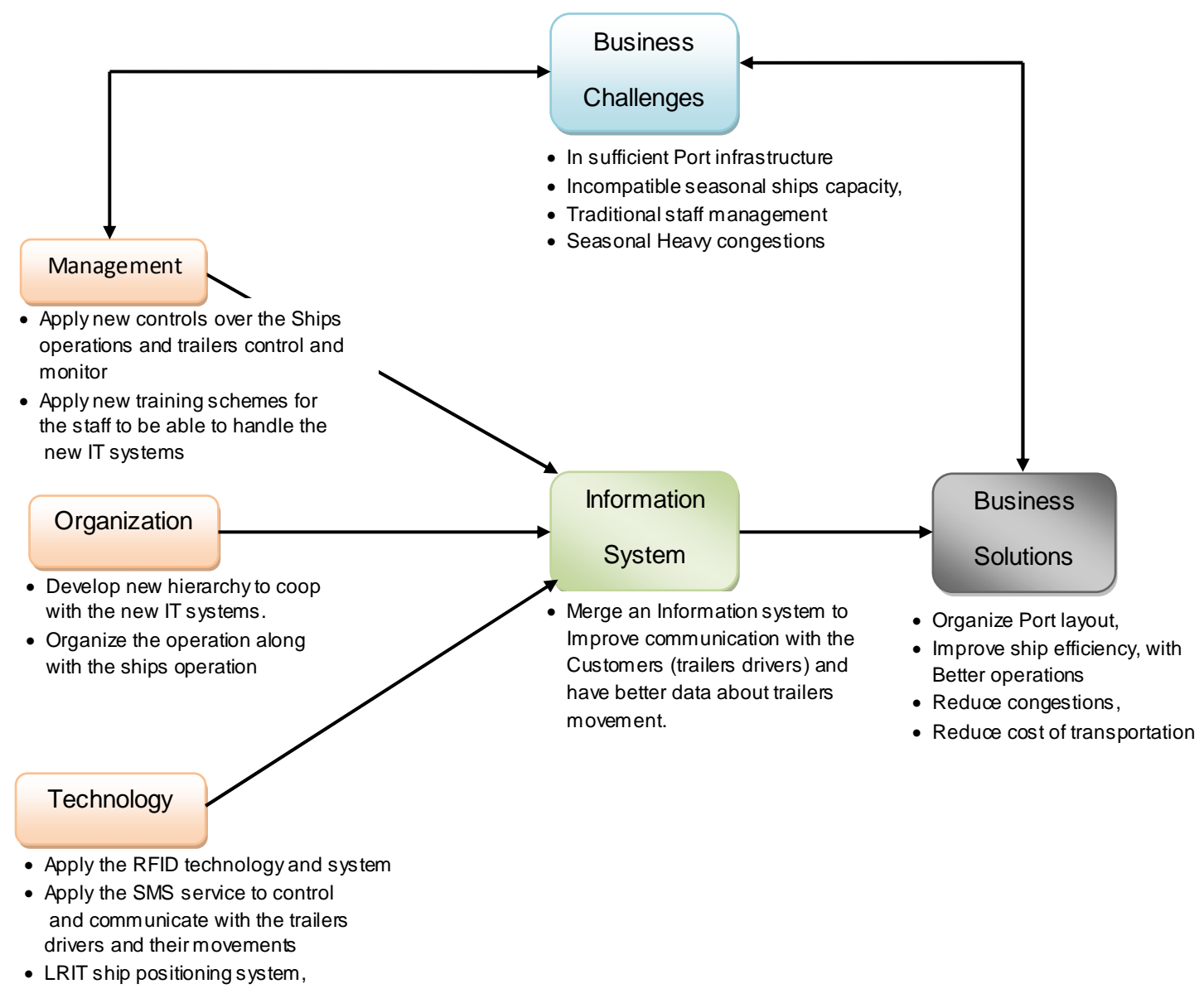

Figure 2. The project main plan of action

\section{Step by Step System Design}

To achieve the target of producing an efficient, cheap and fast maritime and land transportation system over the year, mainly on peak seasons, this research illustrates the application and merging of the three information technologies within its transportation processes as a solution for the ABM business challenges by following a step by step procedure to redesign the required processes and implement it for solving the congestion problem.

\subsection{The First Step; Identifying Business Challenges and Constrains}

The main function of the maritime transport is the carriage or shipping cargo from the port of loading to the port of discharge, on board the shipping production unit which is the ship, depending on its specification such as its type, size, speed and capacity, while the routes (the sea bound trip, distance and weather) and ports (infrastructure, location and facilities) form the other two main elements to be considered if the efficiency of maritime transport is investigated (Jahn et al., 2011).

Eventually the research started the process of analyzing the business challenges and 
constraints within these three elements, taking into consideration the constant growth of the market and international trade between the Eastern and Western Arabian countries across Gulf of Aqaba, In this step the business challenges, obstacles and reasons for trailers congestions at Aqaba Port and Aqaba Free Zone and relevant constrains, were identified and analyzed and the seasonal increase in the trailers numbers was considered as a fact that will continue to grow up even more "The International trade has systemically expanded at a rate larger faster than economic growth” (Rodrigues \& Browne, 2013). See also Figure No.1, showing the trailer's numbers yearly trend of increase.

Therefore, to better identify the reasons for trailers congestions at Aqaba city boarders and Aqaba Port, the principles of TOC process were applied to overcome the constraints and propose the suggested IT technologies as a business solution, and found the following constraints that were identified,

\subsubsection{Insufficient Port Infrastructure}

In general, there are two main problems in the ports, its capacity for handling cargo and its location within the country, as a step of the logistic transportation chain of supply, "the inefficiencies and delays occur at the interchange points at border crossings and along the national transport network result from inadequate infrastructure, inappropriate cargo handling equipment and transport fleets, cumbersome trade procedures, inappropriate management procedures and lack of know-how.” (Aydin et al., 2006).

Therefore, this research focused at the Aqaba Port infrastructure as one of the most important factors affecting on the whole multimodal transport chain of supply, where upon our practical experience in the Port and ABM operations, the following constraints in the trailers flow over the land and maritime transportation systems were analyzed as a direct effect of the Port restricted capacity such as;

\subsubsection{Al Yarmouk Terminal at Aqaba Port}

Aqaba Port lies on latitude 29-31 North, longitude 35-01 East, situated in the far southern end of Jordan on the north shore of the Gulf of Aqaba with about $27 \mathrm{Km}$ long beach only including the ports and public and private beaches (www.globalsecurity.org). This terminal had been moved further south and was eliminated from $150 \mathrm{mtr}$ long 3 terminals berths to a two terminals berth that can accommodate two ships only, this terminal elimination and movement was done for other development priorities resulting in creating a bottleneck to the whole transportation supply chain within the ABM operations, in addition to, a set of restrictions enforced within Aqaba Special Economic Zone Area (ASEZA) to prevent any trailer from entering the Aqaba city urban without a pre-arranged scheduled list to avoid congesting the city itself or used as a parking areas.

\subsubsection{Limited Terminal Capacity}

Yarmouk terminal at Aqaba port is limited by the two berths that can accommodate two ships of restricted size (i.e. about 15000DWT, 150Mtrs long. 7.0 Mtr draft) at a time, this terminal is used for loading all ABM trucks over the year by using a small floating pontoon that "may 


\section{MInstitute Macrothink}

also give some difficulties" because it will affect the operations and turning circles of trailers, especially when there is a vessel at the opposite berth as well and the levels and angles of the ramp may exceed certain limits which limits the operational restrictions” (Arjan, 2012) resulting in longer loading/discharging time and poor loading capacity.

\subsubsection{Restricted and Small Port Area}

To allocate the full load of 50 trucks (one ship load), the terminal parks are also limited where it can handle up to a maximum of 90 trailers every 24 hours, and 17 discharged trailers from a ship at a time, where trailer No. 18 have to stay on board the ship until No.1 trailer moves ahead, this problem restricts the discharging operation of the ship to 4 hours instead of 2 hours. Figure 3, Yarmouk terminal, illustrates the port layout.

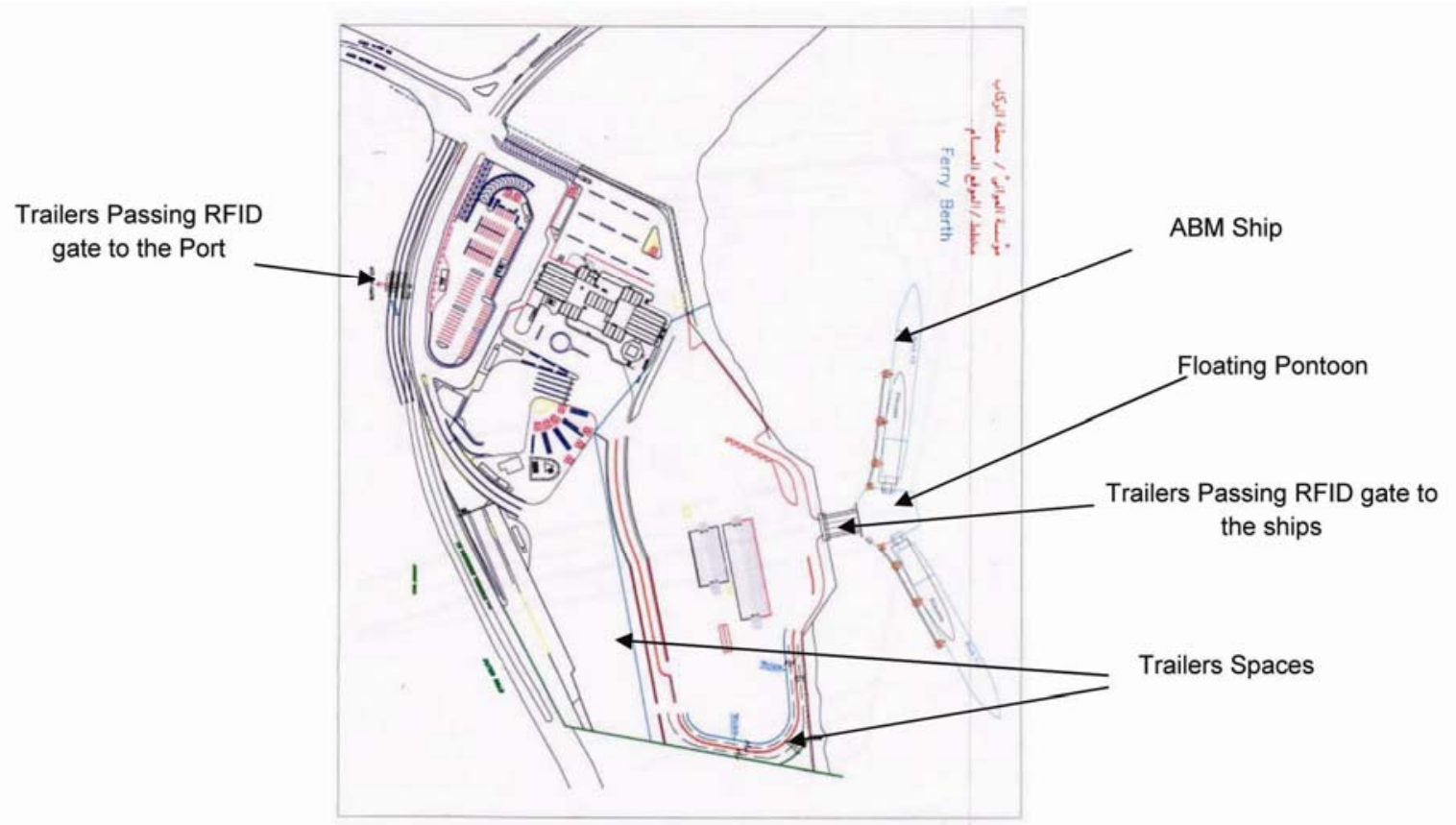

Figure 3. Yarmouk Terminal, Aqaba Port, Jordan Layout

\subsubsection{Seasonal Effect of Trailers Flow on Ships Capacity}

Ships capacity (i.e., number of trailers/weight she can take) is limited, the ABM operates two RORO ships with a capacity of about 100 Trailers load and a speed of 15 Knots, each ship needs about 12 hrs for each round trip (Aqaba, Nuwaibeh, Aqaba). During peak seasons the two ABM RORO ships capacity (Sinaa and Bridge) is insufficient to carry the required load of trailers in time due to large number of trailers arriving to the two ports almost 150/170 trailers/day from each side, results in adding about 50 to 70 trailers to the already waiting trailers every day, for about 6 months (from October to April every year- Cargo peak season, see figure 1), even with the best utilization of ships capacity around the hour, these two ships with a max of 5 trips every two days were never enough to handle such huge amounts of demand because of the limited terminal space. However, practically, the best possible way is 
either to purchase or charter a vessel (additional capacity) which may not always be available in the correct time, required size and good hiring rate or to optimize ships operation schedule and perform additional voyages. Practically increasing the ABM ships loading capacity and efficiency by balancing the ship tracking and trailers flow.

\subsubsection{ABM Operations}

Due to the traditional management traditional practices (i.e., lack of feedback, control and monitor systems, low stevedoring standards and poor communication practices) the operation department staff suffered practical problems in overcoming the operation environment, surrounding constraints and the ability to control trailers flow, improve their loading practices efficiency and increase ships voyages.

\subsubsection{The ABM Customers Culture}

Trailer's drivers are not highly educated people, face a lot of driving problems and pressure on the roads, their need to keep moving ahead keeps them highly alerted and sensitive to obstacles, where they easily create problems and sever objection actions once they are delayed for few days due to congestions in the port with all related losses they encounter due to delays and waiting times. In our case, drivers are not permitted to move down to the port or leave the trailers park without a prearranged lists of trailers (50 each), this listing process is organized and executed by a contractor who releases the trailers to Trailer's Park No.1 after receiving the ABM confirmation of their ability to load the available load of trailers on board the available ship at berth. Eventually with the limited port facility and ship capacity, drivers have to place their turn at Al Rashdiayh area (a deserted area $35 \mathrm{~km}$ north of Aqaba on the International street between Amman and Aqaba) and keep waiting for days (Figure 13, Aqaba Area layout) until being moved by ABM ships across the sea. These waiting times may extend to several days, where driver's dissatisfaction creates great objections, demonstrations and problems that affect on the company reputation. Therefore this research took into consideration the critical relationship between the ABM and its customers (trailer's drivers) as a very sensitive problem that can be partly solved by utilizing a better communication standards, and continuous feedback to update the trailers drivers with the ABM operations with the relevant information required to avoid bringing them to the deserted area of $\mathrm{Al}$ Rashdiyah until their date have come.

To partly solve these problems, our main target was to bring our interests in providing the cheap, effective and fast transportation systems along with our customer's interests and needs where we can work together rather than against each others. Therefore, this research based on the fact that even with our customer's poor IT culture we still have the chance to identify and allocate the proper IT system to improve the ABM level of communication with the trailers drivers, and wherever applicable the research adapted different levels of ITC simple models.

\subsection{The Second Step; Identify and Utilize the IT Systems}

The use of Information and Communication Technology (ICT) speeds up the exchange of information and especially integrated applications of MIS, GIS and GPS/GNSS are necessary to be introduced in multimodal transport and Supply Chain Management (Ayden et al., 2006). 


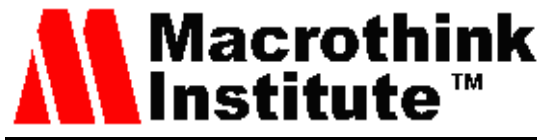

Technology can also be viewed as external driver of change in most organizations since the rapid development of technology (hardware and software) and its application by individual forces companies to change and adapt; otherwise they may perish (Coyle et al., 2011). At this stage, it was very important to identify, Invest, apply and emerge the three IT technologies the LRIT, SMS and RFID within the ABM operations processes and build the required IT infrastructure to achieve business solutions, therefore, the research concentrated on exchanging a relatively cheaper and more available technology and IT applications in the market such as the LRIT, RFID and SMS with heavily expensive Geographic Information Systems (GIS) and Global Positioning System (GPS), to build the required IT infrastructure and solve the company's problem by applying the RFID, LRIT and SMS technologies within the ABM operations.

To track the ABM ships and incoming trailers, the new processes may be viewed as an internal changing action since it can enhance the efficiency and effectiveness of the whole ABM operations and arrange for the best flow and collaboration between these technologies to control the trailers and drivers on their travelling and movement on the roads.

As a result, this research took into consideration to study these three suggested Information Technologies, analyze, study and evaluate its ability and capacity for being used, merged and applied for the ABM operations and introduce the required business solutions and solve the constraints discussed in Step one.

These three communication technologies and systems are;

\subsubsection{RFID, Radio Frequency Identification Technology}

This technology has emerged as one of the hottest technologies in supply chain management today (Lee \& O"zer, 2007), The RFID is a relatively cheap automatic data reader, the RFID tag (Figure 5, www.dhs.gov) is also smaller in size and easy to handle than the GPS instruments with no need of human interference than the Bar Coding system, it keeps the track and take the note on how many times the trailer passed over a certain Gate and perform simultaneous read of multiple objects. It can be used for the day to day operation with wider reading ranges and larger memory capacity; it is a powerful emerging technology (Surendra, http://gjmr.org/).

The RFID was placed within the system framework, See figures 6, (a) and (b), where the following elements/systems had been installed/optimized and used to put it on operation,

\subsubsection{The Hardware}

The hardware contains the RFID tags, Readers, gates, host controller and cabling, (i) The RFID Tags; these are mobile gadgets with digital memory chip and unique ID codes that broadcasts data, which are then read by tag readers, it contains the Chip, the antenna and the backing material (Figure 5, RFID Tag), (Surendra, http://gjmr.org/). 


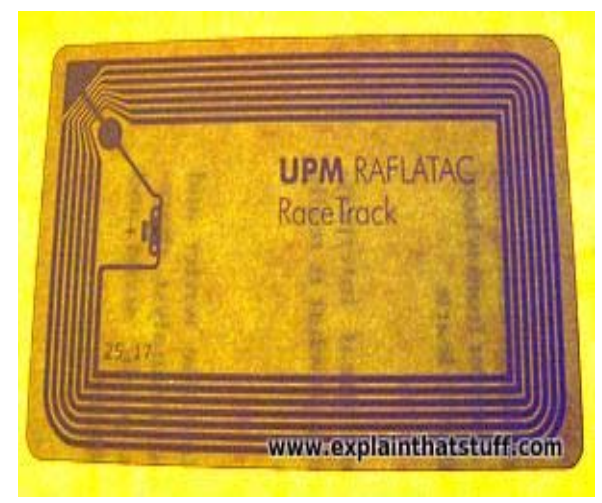

Figure 5. RFID Tag

When the RFID tag passes through the field of scanning antenna, it detects the activation signal from the antenna that "wakes up" the RFID chip and transmits the information on its microchip; this signal is picked up by scanning antenna. Then the reader passes this information to a processor for processing and storing the obtained information. For transmitting its data the RFID uses the radio frequency range from $50 \mathrm{~Hz}$ to $2.5 \mathrm{Ghz}$.

There are three types of RFID tags, the Active tags, a RFID Chip with a power supply impeded in to allow a very low level signal to be recovered by the tag, this tag generates high level signal to the reader allowing a reading distance of 15 to 25 meters and operate in a frequency range of $860-960 \mathrm{MHz}$, the Passive tags type that does not need a power source, therefore they are smaller and less expensive than the active tags. When it comes in reader field, it draws power from the magnetic field that allows it to reflect the Radio signal transmitted to them from the reader. These tags allow for a reading distance of a $5 \mathrm{~cm}$ to 20 $\mathrm{cm}$ and operate in a frequency range of $860-960 \mathrm{MHz}$, and the Semi-Passive tags, this type is fitted with a small battery as a power source and functions in comprising both passive and active tag properties, where it enjoys, 100 times greater sensitivity than passive tags, longer battery life cycle than active tags and actively function under its own power even when no reader is present to power the circuitry. when passing in (ii) The RFID tag readers and Gates; it communicates with the RFID tag through its transmitted radio frequency signal via its antenna to the receiver's antenna, it supplies power to the passive RFID tag, and interprets the digital signal received with the data set on the Tag through its operating software, then transmits these information to the (iii) Host Controller, that can be a computer or Laptop, close to the reader, and can manage several readers, after receiving the data from the reader/receiver, it processes it (i.e. filtering and collation) and saves it, with up to date instructions, in addition to securely controlling the device and monitors the reader's functions. This controller is connected to the readers through networking technologies (iv) (TCP/IP), the Transmission Control Protocol/Internet Protocol or a serial connectivity configured with the required operating system to carry out the relevant requirement, depending on the data volume from those readers and computer storage capacity. The system needs the proper cabling set according to the distance between reader and host computer by the proper $(v)$ the Cabling (Surendra, http://gjmr.org/). 


\subsubsection{The Software, RFID Middleware}

This is the operating software that facilitates communication between RFID readers and enterprise systems. It collects, filters, aggregates and applies business rules on data received from readers. Middleware is also responsible for providing management and monitoring functionality ensuring that the readers are connected, functioning properly, and are configured the correct way. IT may also contain a localized data store for archival of read events (www.dhs.gov).

As a system, the Software, The RFID tag and Readers are operated by an operation system (software application programming interface (API) supplied by the reading Gate provider (manufacturer from the market) for any required configuration and setting, see figure 6 (a) and (b) describing the RFID technology.

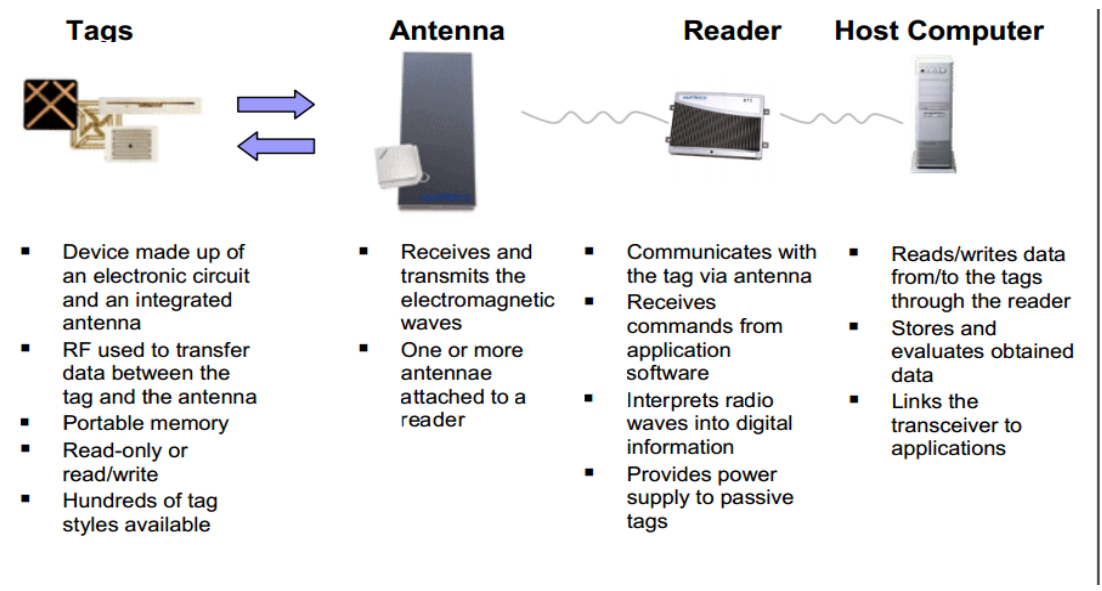

Figure 6a. Passive RFID tag technology description (Dalu, 2007)
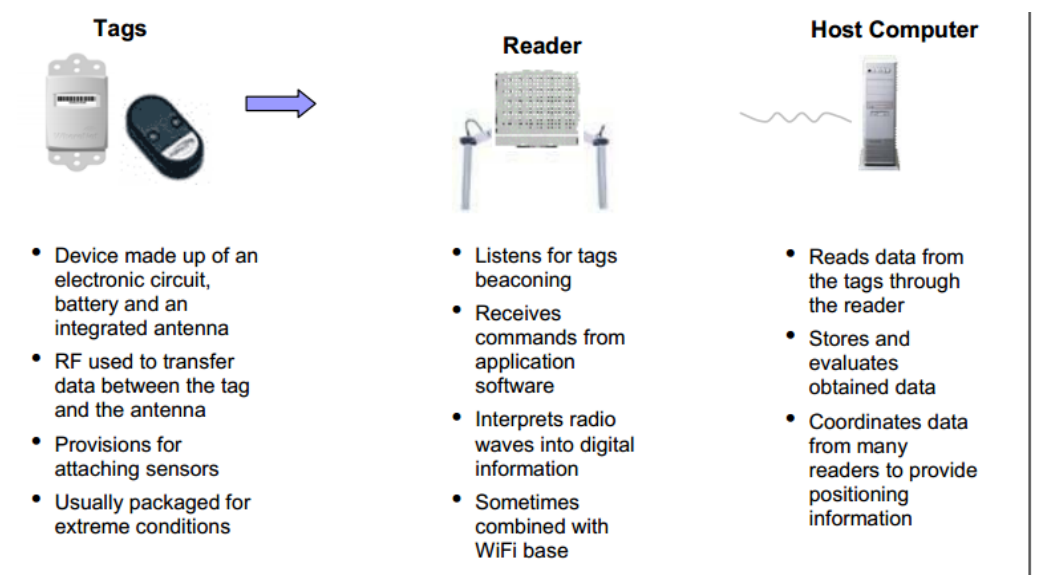

Figure 6b. Active RFID tag technology description (Dalu, 2007) 


\subsubsection{SMS, Mobile Phones Short Message Service}

This SMS technology enables sending and receiving messages between mobile phones, or between a communication center and the mobile. There is vast useful commercial and social utilization for SMS, it can be used without IT infrastructure because the SMS Messages sent from the company should reach at users' mobile phone through SMS gateway of service providers (ZAIN). The SMS gateways transfer the messages from Zain, http connection Web Site, to SMS and pass it to the mobile service providers. This technology of the SMS gateways of sending messages to users via the Web also receives user responses via SMS. (Kumar et al., 2008).

Figures 7 (a) and (b) also show the SMS technology using the gateway, while Figures 8, and 9 show ZAIN web leased page by ABM and the messages intended to be sent to the drivers. This technology is too cheap as it is sold for $0.01 \mathrm{USD} /$ message.

The necessary investment for such a system is quite low, the designers only need a mobile phone connected to a computer, and then to design or lease their own program or web site to receive and respond to messages. Microsoft Research has even designed an interface called the "SMS Server Toolkit" to assist software developers in designing such a program. Furthermore, there is nothing special to deploy to end users; they just need to be informed of the special number to message and how to contact it (www.microsoft.com).

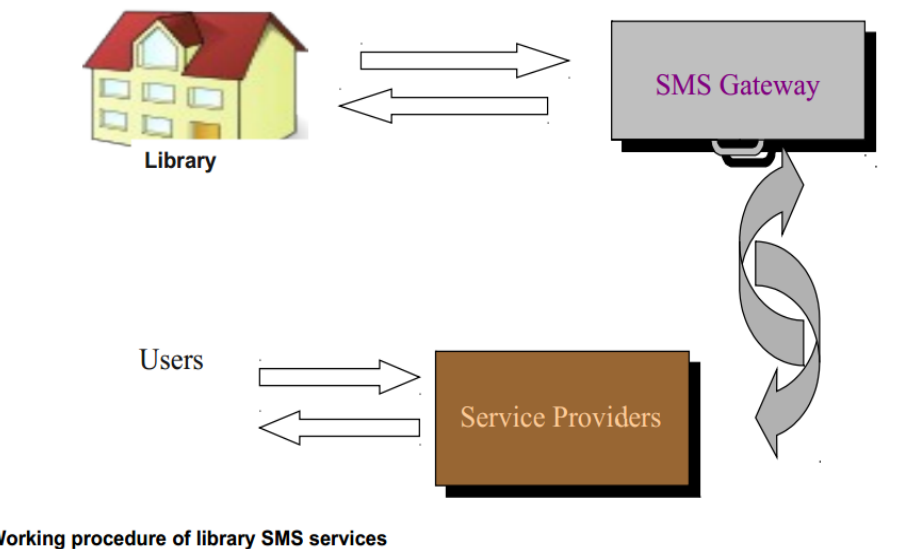

Figure 7a. the SMS working technology(Kumar et al., 2008)

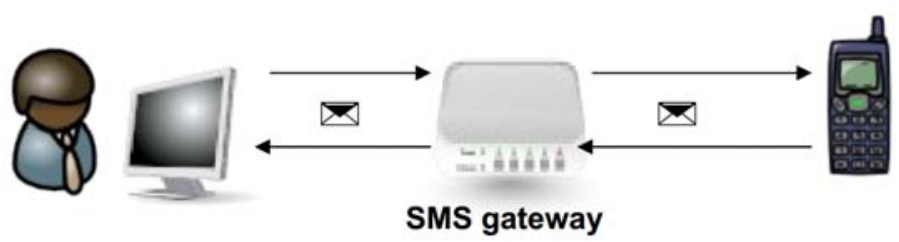

Figure 7b. The SMS working technology (Kumar et al., 2008) 


\section{Macrothink}

In Jordan and according to Alomari et al. (2013), the government developed a SMS gateway aims to increase the effectiveness of communication channels between government and citizens, the m-government interacted with the citizens from the beginning of 2008 to 2011 more than 32 million messages, In this project, the government used two types of message techniques, the Pull messages: where services are requested by the citizen when sending a message requesting for a piece of information or service through the number 94444 and then the citizen receive message related information or services that inquire about the relevant department and Push messages (toward users); where messages are sent by the government to citizens without their request, such as reminders, awareness campaigns, information on the status of the transaction, and provide citizens with information about the governmental departments and services (Alomari et al., 2013).

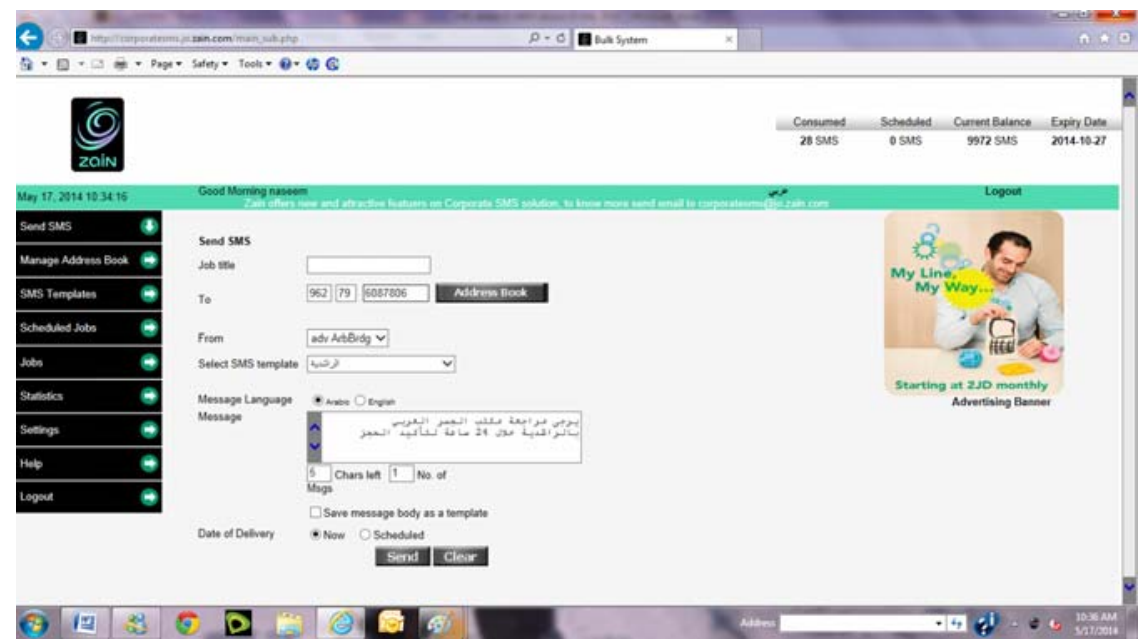

Figure 8. The ABM leased web page with the SMS

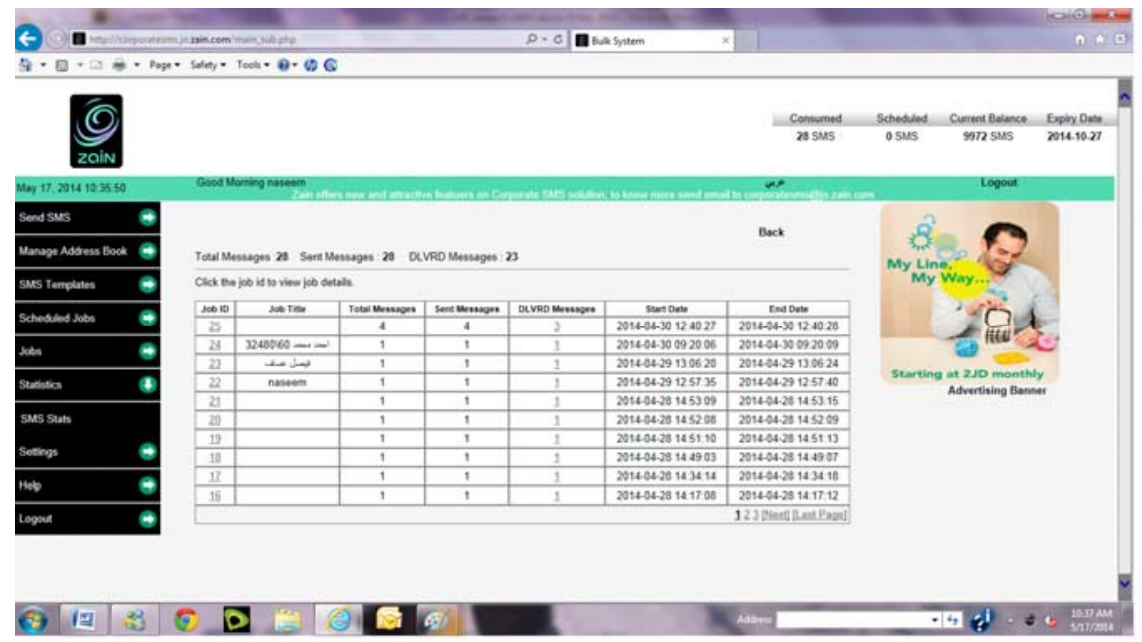

Figure 9. List of ABM trailers groups 


\section{Ml Macrothink}

Case Studies in Business and Management

ISSN 2333-3324

2014, Vol. 1, No. 1

As useful mean of communication, in our case we will be using the ZAIN website for grouping the trailers and listing them on their turns in addition to setting the required message to be sent to the driver, the Push messages technique, in the correct time (36 hours before vessel Estimated time of Departure) to attend the ABM offices and move down to the trailers park No. 1, then to the Yarmouk terminal at Aqaba Port, this process will avoid trailers physical attendance to Alrashdiya where that can keep waiting at their most suitable location (home, customs yards in Amman, or special waiting parks reducing their waiting cost and long backhauls).

\subsubsection{LRIT, the Long Range Identification \& Tracking (LRIT)}

This system had been adapted by the International Maritime Organization as an obligatory requirement used to keep ships on track and under continuous surveillance and follow up, where a transmitter fitted on board the ship transmits the ship's data, position, and date and time by sending a signal at $1626.5 \mathrm{MHz}$ to $1660.5 \mathrm{MHz}$ to Inmarsat C, Iridium and Isat M2M - satellites, this signal is then transmitted through a service provider and Data Center to the Port State Control, Coastal States and Flag State in addition to keeping the data in a storage server for further use. However, the communication companies developed several tracking systems such as the Automatic Identification System (AIS - figure 10).

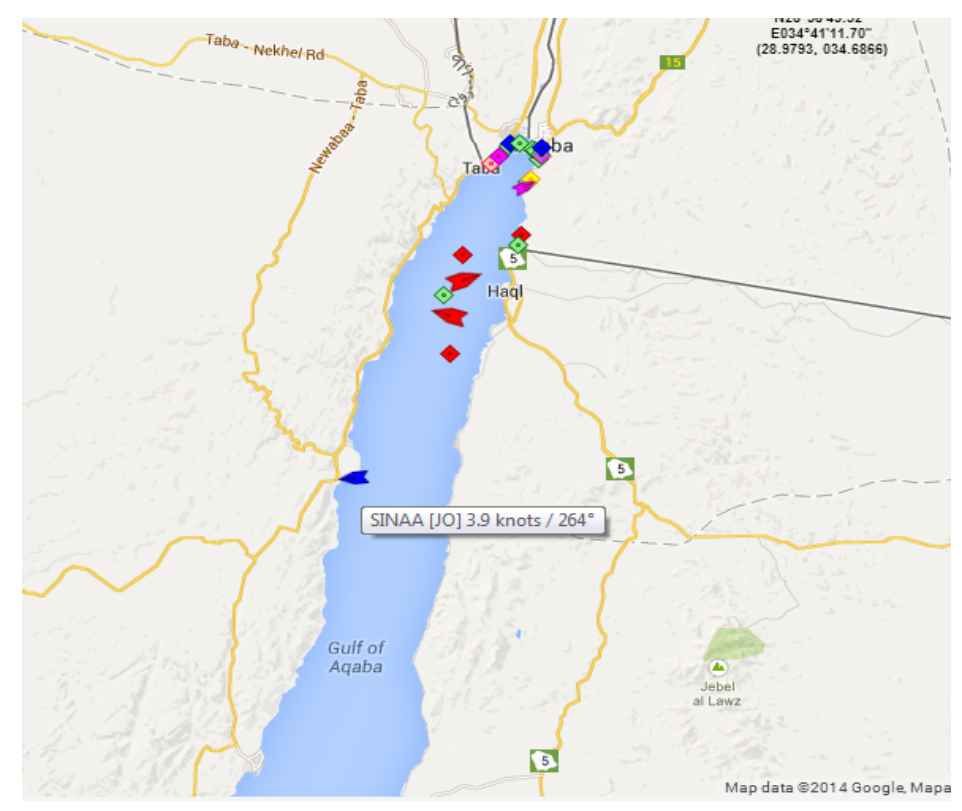

Figure 10. AIS tracking system Gulf of Aqaba

But due to some security difficulty and the massive amount of information and ships icons on the map, the ABM arranged with a service provider (www.satpro.org) to keep tracking the ABM ships by installing a transmitter on board the ship, with a monitoring dashboard or screen at the ABM Operation office to keep tracking the ships on its route at Gulf of Aqaba on 15 minutes intervals (see figures 11 and 12). 


\section{LRIT Architecture Diagram}

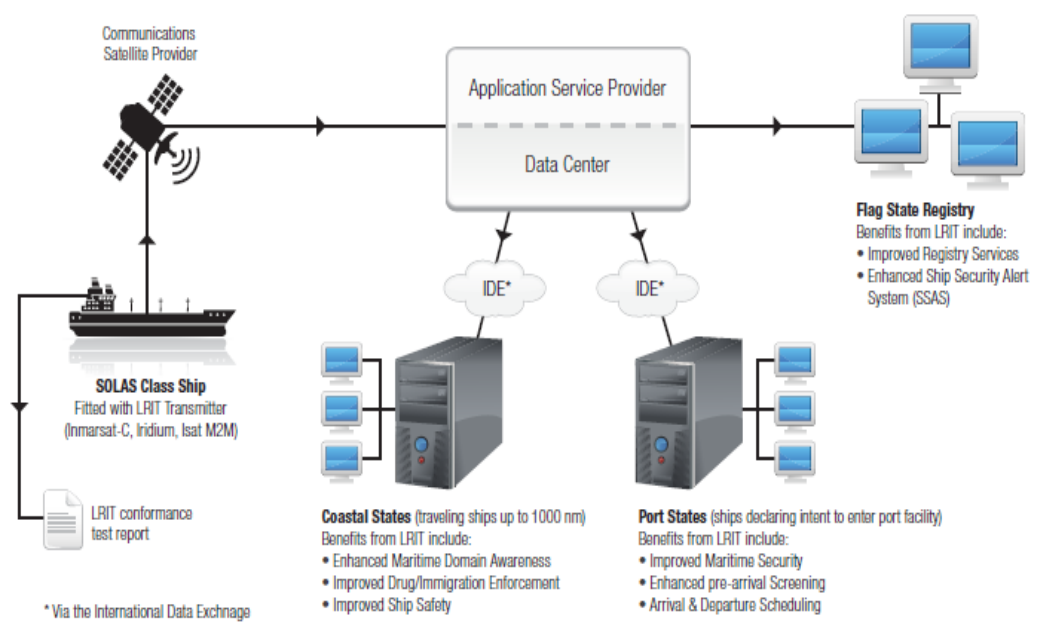

Figure 11. LRIT absolute maritime tracking system Inc.

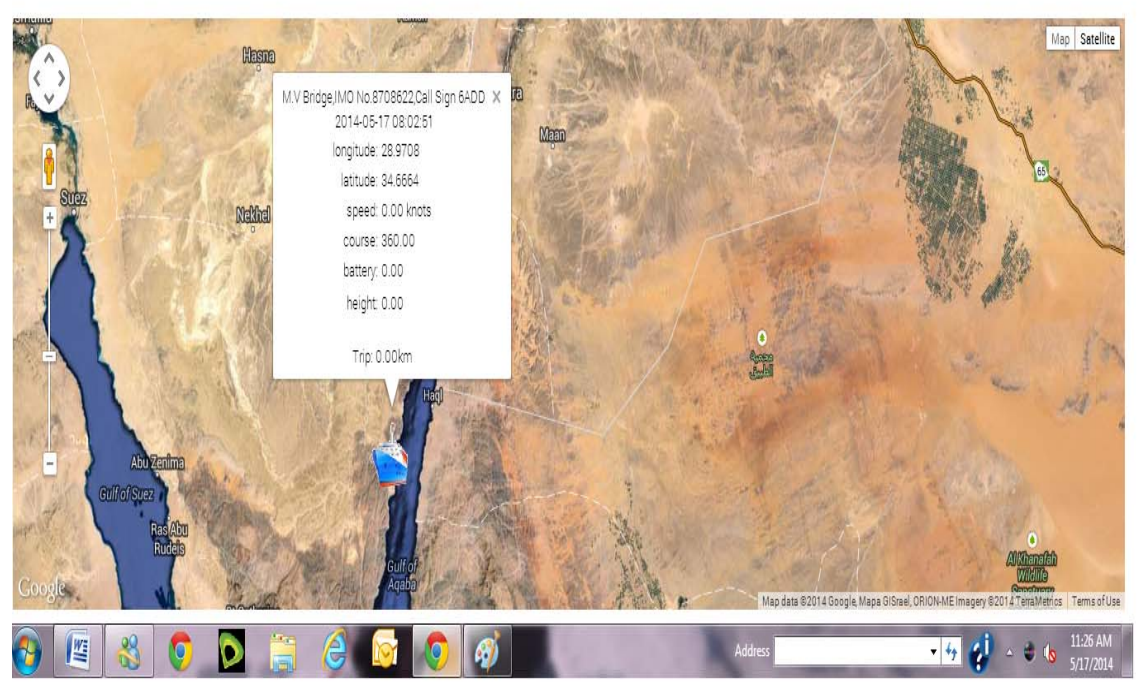

Figure 12. ABM ship’s tracking and LRIT system

This system was used efficiently for tracking the ABM ships on real time bases where the ABM operation manager was able to follow up the ship's movement on short notice and take the necessary decision with the correct list of trailers and bring the listed trailers to the loading Yarmouk Terminal at Aqaba Port on the correct time. 


\section{Macrothink}

\subsection{The Third Step; ABM Organization and Processes}

In this step, the necessary changes to the relevant company processes were identified and applied, at operation department Management and Organization levels including levels of responsibility and communication practices (See figure 16 and table No.1).

To apply these systems within the overall company activities, the changes started at the organization hierarchy, where the operation department was divided into four main sections, all of which were assigned under the direct management of the Operation Manager,

1. Shipping/Loading and discharging department,

2. Manifest Department

3. Park No.1 Department

4. Sales Department

This new management hierarchy was designed to have a better feedback and control over the land, and the maritime transportation facilities that enable the Department on handling the new trailers movement management and the ship operation Management; the table No.1 illustrates the new responsibility and offices duties within the new system.

Table 1. The new ABM operation staff duties

\begin{tabular}{|c|c|}
\hline Position & Duties \\
\hline ABM Operation Manager & $\begin{array}{l}\text { Set the Ships schedule and time table } \\
\text { Arrange the required ship according to its capacity } \\
\text { Carry out the day to day operations } \\
\text { Follow up the trailers movement and statistics } \\
\text { through the FRID electronic gates }\end{array}$ \\
\hline ABM Park No.1 Office & $\begin{array}{l}\text { Register the trailers turn } \\
\text { Coordinate with the ABM Loading Supt for trailers } \\
\text { movements } \\
\text { Arrange for Booking and Loading permission }\end{array}$ \\
\hline $\begin{array}{l}\text { ABM Loading } \\
\text { Superintendents in } \mathrm{Al} \\
\text { Yarmouk terminal at aqaba } \\
\text { Port }\end{array}$ & $\begin{array}{l}\text { Coordinate with the ABM park officers for trailers } \\
\text { movements down to Aqaba port } \\
\text { Follow up the daily loading procedure on board the } \\
\text { ships } \\
\text { Keep the full load of a ship at the Port ready for } \\
\text { loading on ship arrival }\end{array}$ \\
\hline ABM booking officer & $\begin{array}{l}\text { Issue the relevant booking and shipping documents } \\
\text { and double check the trailers specifications and } \\
\text { ticket value }\end{array}$ \\
\hline ABM FRID Tagging Office & $\begin{array}{l}\text { Issue the FRID with the Trailer and driver data and } \\
\text { stick the same to his truck } \\
\text { Secure the electronic gate data }\end{array}$ \\
\hline
\end{tabular}




\section{Macrothink

\section{Trailers Feedback and Control Process}

This process was divided into several operation procedures integrated by the relevant IT system required on each procedure of the ABM operation to get the best of the proposed ship and land transportation systems, as follows,

\subsection{Arrival ASEZA}

The Trailer/Driver arrive ASEZA from three directions, the Dead Sea Road, Amman Aqaba International road and the Jordanian Saudi Boarder at Al Derreh where it will be registered by the relevant RFID gates at each entrance (figure 14).

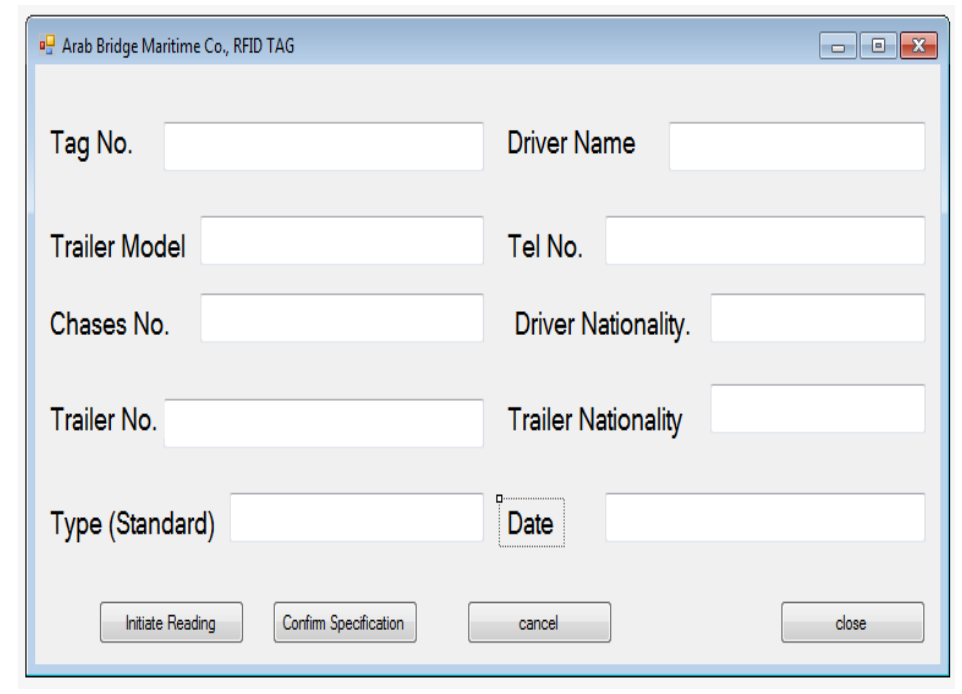

Figure 14. ABM developed RFID TAG

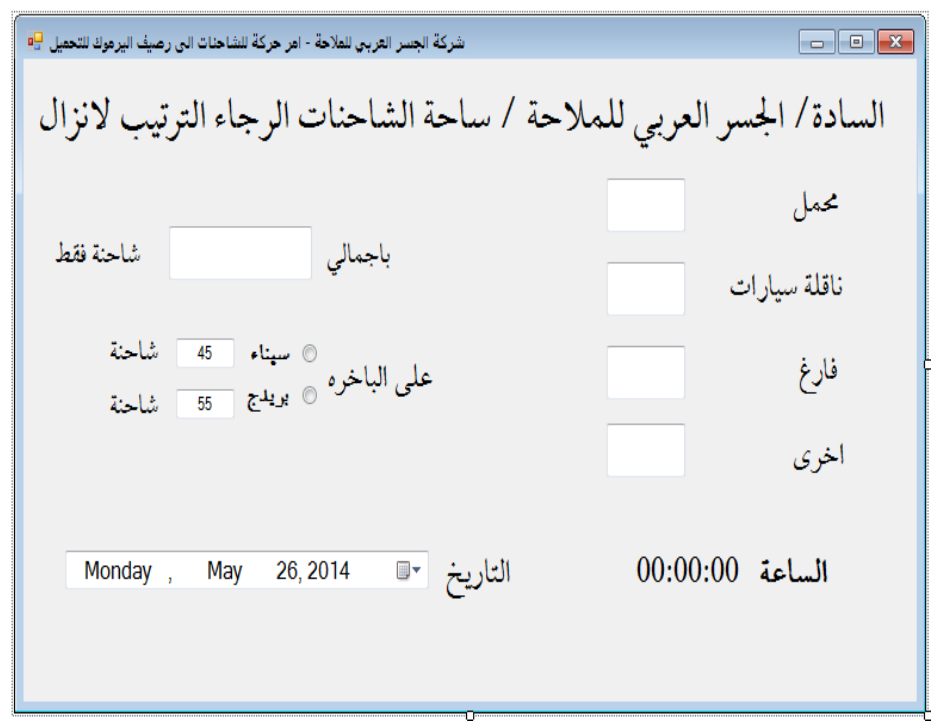

Figure 15a. Operations trailers loading order 


\subsection{RFID Registration}

For the first time the driver should attend the ABM office at Al Rashdiyah to register his data and get the required RFID Tag with his trailer's specifications, such as Truck No., Type (i.e., reefer, standard, empty, car carrier....etc) either loaded or not, fix it on the window, then to register his turn by the ABM booking officer, on ZAIN web page at the date of his attendance group, the ABM officer should also check his data against the RFID tag.

\subsection{Leaving Alrashdiyah}

Upon completion of registering and getting the RFID Tag, the trailer driver may leave back home instead of staying in the deserted area at Al Rashdiya until being called by the ABM SMS message to move to the Trailers Park No.1 otherwise he has to stay stay waiting for his turn that may take 6 to 7 days, on this option, trailers congestion will drop to less than 200 trailers (two days ship load).

\subsection{SMS Alert Message}

Once called by the SMS message (figures 8 and 9), the Trailer/Driver should proceed from his home, or Alrashdiyah to the Trailers park No.1, where the trailer should pass the RFID gates at each park, then to be traced by the Operation Department for its movement along the system and follow up the numbers of the trailers on move.

\subsection{Moving to Trailer Park No.1}

At the Trailers Park No.1, the Trailer/Driver should weigh his car, book his ticket and issue the loading permit, and wait until being called again by the SMS system to move down to the Port, this process will take about 48 hours Max, where he can finish some of his cargo customs declaration and relevant matters.

\subsection{RFID Gates Follow Up}

Upon his movement, both RFID gates should also register trailers movement to the ABM Operation Manager monitor to know the location of the trailers

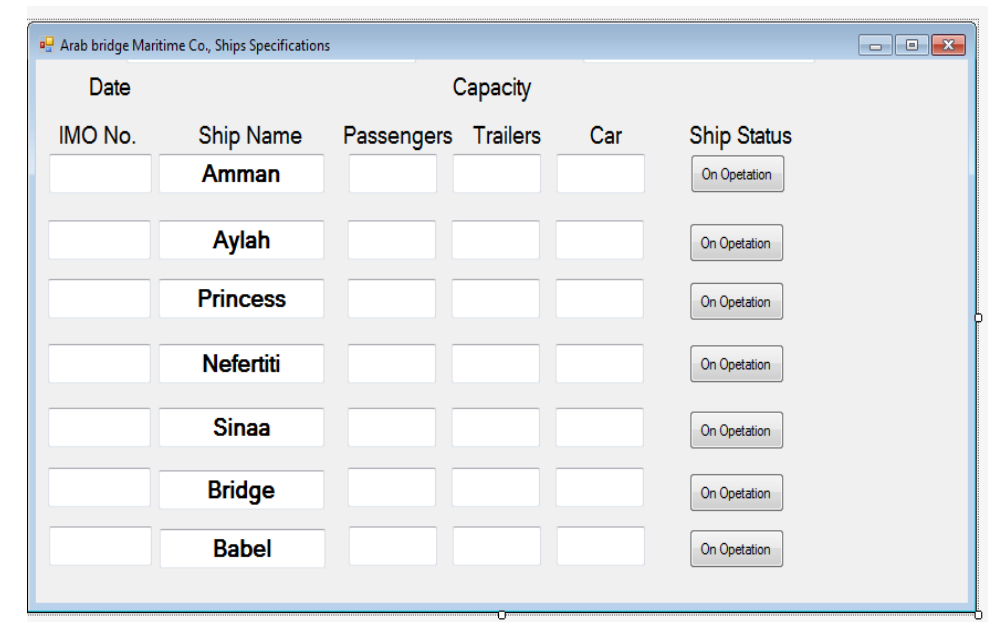

Figure 15b. Ships specification screen 


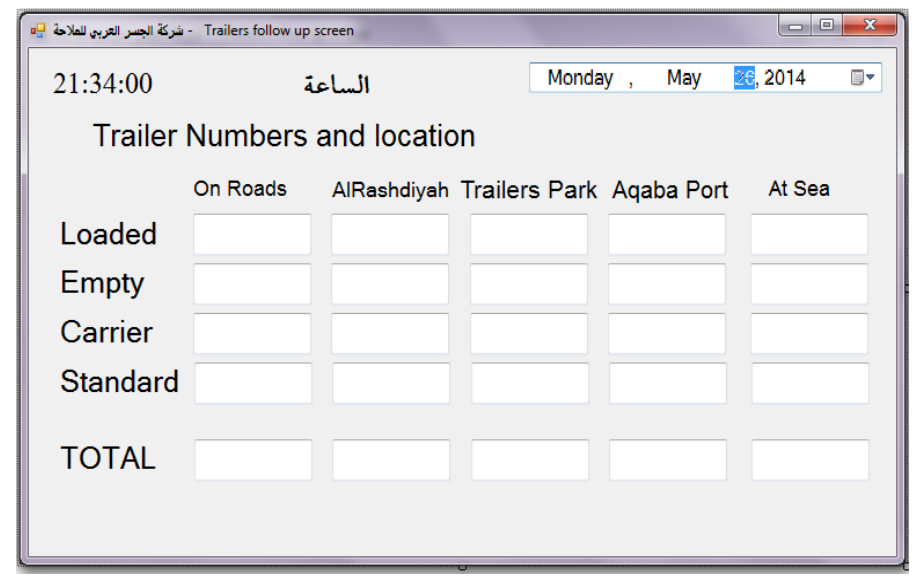

Figure 15c. Trailers follow up screen

\subsection{ABM Operation Management}

The ABM Operation Manager should check the ship's schedule and set up the required list of trailers he can load on board the assigned ship specification and upon the RFID data and trailers specifications (Figure 16).

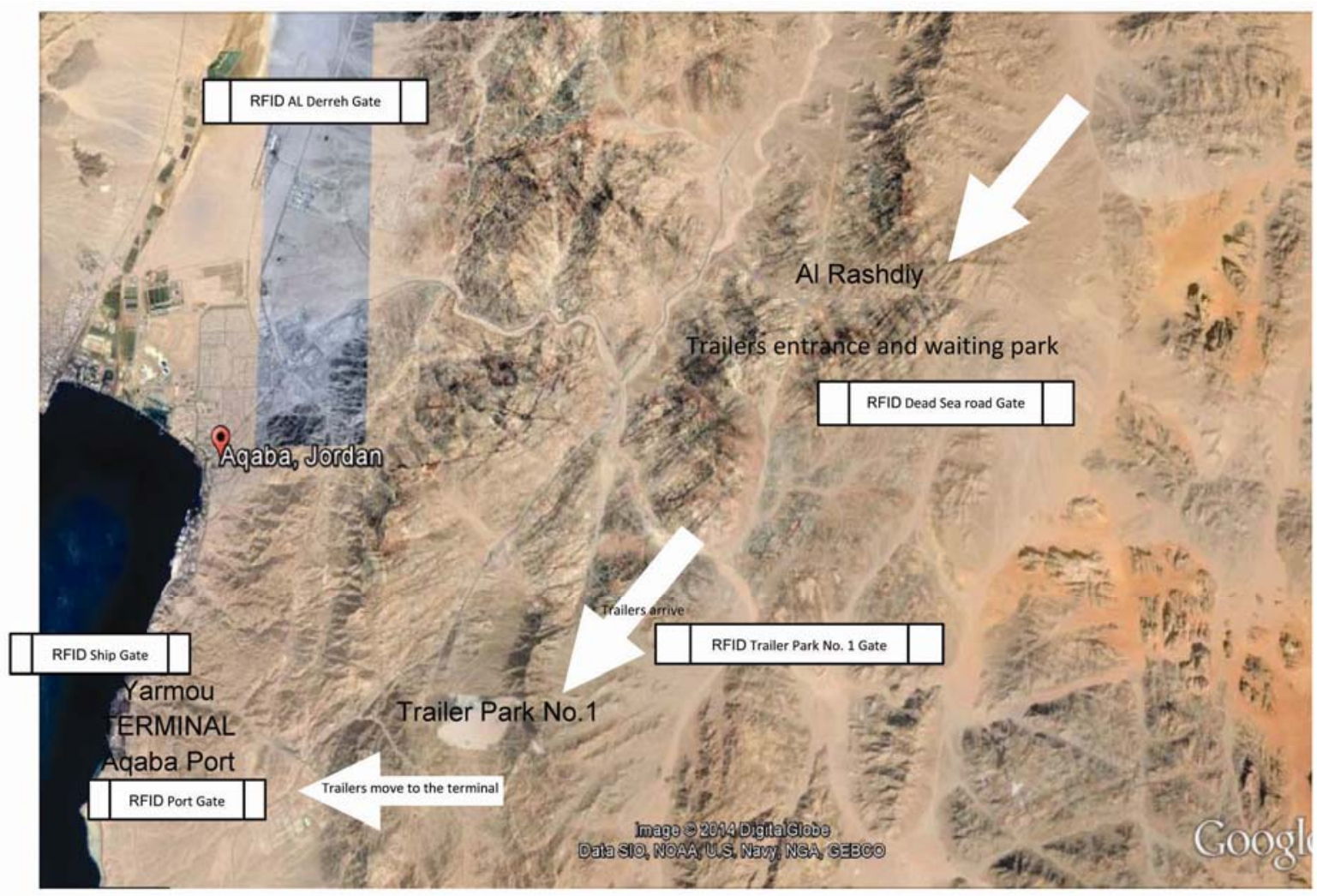

Figure 16. Aqaba Area Layout and trailers moving track 


\subsection{Organizing Sailing Time}

In the meantime, the Operation Manager should have organized and set the sailing time table for the ships with the relevant capacities and inform the ABM Officer in Trailers park No. 1 with the daily situation in the Port area.

\subsection{Trailers Loaded on Ships}

After completing its customs procedures, and other port formalities, the trailer can be loaded on board and should also pass the last gate to show that it had already left the whole system.

By using the trailers follow up screens/dashboards, the RFID and LRIT systems should provide the ABM Managers with an updated list of the trailers in each location and organize their time tables (figure 15c), he should be able to follow their movement and actual numbers in the parks rather than just getting the information on the phone, These dashboards will be developed and customized to the ABM requirement and real-time follow up for the trailers positions and numbers

The Swim lane Flowchart method figure 16, used to illustrate the logical flow of processes and relevant responsibility physically and within different time zone.

\section{Conclusion}

The application of the (LRIT, SMS and RFID) within the ABM operation procedures avoided trailers congestions, saved manpower and company resources by providing the ABM operation Manager and staff at all levels with the proper monitoring, feedback and control tools and means to organize and manage the transport chain of supply on land and at sea, despite the limited port infrastructure and ships capacity. Upon facing problems, the ability of a company to adapt the necessary decisions and actions, including the reengineering part of its processes and merging of new Information Systems to overcome the challenges facing the company, and efficiently mobilize its resources may not at certain times (i.e., seasonal) add competitive advantage and operational excellence values only, instead this ability serves as an essential survival element for the company, and turns from being an option to be an imperative decision for existing in the highly competitive market or special working condition without which the company will collapse.

However, the environment surrounding the whole operation should keep us ready to perform other researches to keep improving this service and look into the root cause of the customer's dissatisfaction, including more advanced IT solutions and other related operation constraints solutions, to end up with an unseen mutual interest terms between the ABM and its market.

\section{Acknowledgements}

The research is performed as part of the MBA program requirement for at the University of Jordan, Aqaba Branch, with great thanks to Dr. Evon AbuTayeh for her support and continuous advice and Dr. Feras Al Rawashdeh the head of Administration and Finance college in the University for his support for the MBA program. 


\section{References}

Alomari, M., Elrehail, H., \& Al Shibly, H. (2013). Mobile-Government: Challenges and Opportunities, Jordan as Case study. Journal of Business and Social Science, 4(12).

Aqaba Development Corporation ADC. (2014). [Online] Available: http://www.investopedia.com

Arab Bridge Maritime Site. (2014). [Online] Available: http://www.abmaritime.com.jo/en/the-fleet

Arab Bridge Maritime Statistics. (2009 to 2013).

Aydin, A. O., Onwuka, K. O., \& Sarman, S. (2006). Supply Chain Management: The Role of Trading Systems. Paper presented at the 2nd International Conference on Business, Economics and Management, Izmir, TURKEY. [Online] Available: http://www.globalsecurity.org/military/facility/port-aqaba.htm

Coyle, J. J., Novack, R. A., Gibson, B. J., \& Bardi, E. J. (2011). A supply chain perspective (7th ed.).

Jahn, C. (2011). Efficiency of maritime transport A system approach from the logistics perspective. Fraunhofer Center for Maritime Logistics, Germany.

Krajewaski et al. (2013). Operations Management Processes and Supply Chain (10th ed.).

Kumar, K. V. (2008). IASLIC 23rd National Seminar on "Library Profession in Search of a New Paradigm”. Bose Institute, Kolakata, Innovative use of SMS technology for the excellence in library services in Thiruvananthapuram Information Centre Tata Consultancy Services.

Laudon \& Laudon. (2013). Management Information System. Pearson Education Ltd.

Lee, H., \& O“zer, O“. (2007). Unlocking the Value of RFID. Production and Operations Management, 16(1), 40-64. http://dx.doi.org/10.1111/j.1937-5956.2007.tb00165.x

LRIT Absolute Maritime Tracking System Inc. (2014). [Online] Available: http://satpro.org/kundenlinks/concilium.php

Majchrzak \& Wang. (1996). Breaking the functional mind-set process organizations.

RFID Tag Technology Description. (2014). [Online] Available: http://explainthatstuff.com

Rodrigues, J., \& Browne, M. (2013). International Maritime Transport and logistics. University of Economics Geography.

Sherry, J. M. (2009). Mobile Phone applications, information technology for individuals in the developing countries. [Online] Available: http://research.microsoft.com

Surendra S. Intelligent application of RFID for locker security in banks. Dalu International Journal of Research in IT, Management and Engineering. 


\section{Macrothink}

Valacich \& Schneider. (2013). Information Systems Today; Managing Digital World (6th ed.).

\section{Glossary}

RFID : Radio Frequency ID,

SMS : Short Message System

LRIT : The Long Range Identification \& Tracking

RORO : Roll on Roll Off ships, HSC : High Speed Crafts.

\section{Copyright Disclaimer}

Copyright for this article is retained by the author(s), with first publication rights granted to the journal.

This is an open-access article distributed under the terms and conditions of the Creative Commons Attribution license (http://creativecommons.org/licenses/by/3.0/). 